\title{
MODAL SOSIAL PADA PENGELOLAAN DAN PELESTARIAN HUTAN MANGROVE DI KECAMATAN LABUHAN MARINGGAI KABUPATEN LAMPUNG TIMUR
}

\section{(SOCIAL CAPITAL OF MANGROVE FORESTMANAGEMENT AND CONSERVATION IN LABUHAN MARINGGAI DISTRICT OF EAST LAMPUNG REGENCY)}

\author{
Evi Juita K. Nababan, Rommy Qurniati, dan Asihing Kustanti \\ Jurusan Kehutanan Fakultas Pertanian Universitas Lampung \\ Jln. Prof. Dr. Soemantri Brojonegoro No. 1 Gedung Meneng Bandar Lampung \\ E-mail : evijuitak_nababan@yahoo.com \\ No. Telepon : 082179368160
}

\begin{abstract}
ABSTRAK
Pengelolaan hutan mangrove berkelanjutan membutuhkan modal sosial. Salah satu modal sosial adalah melakukan hubungan satu sama lain dan menjadi kekuatan yang penting bagi kehidupan ekonomi masyarakat dan eksistensi sosial lainnya. Penelitian ini bertujuan untuk mengetahui karakteristik sosial ekonomi dan modal sosial masyarakat dalam mengelola dan melestarikan hutan mangrove di Kecamatan Labuhan Maringgai Kabupaten Lampung Timur. Penelitian menggunakan analisis kuantitatif dan kualitatif. Metode yang digunakan yaitu metode scoring dan deskriptif. Hasil penelitian menunjukan bahwa karakteristik sosial ekonomi di Desa Margasari mayoritas memiliki persamaan dengan Desa Muara Gading Mas dan tingkat modal sosial pada kelompok masyarakat di Desa Margasari dan Muara Gading Mas adalah rendah karena unsur-unsur modal sosial dalam penelitian mayoritas rendah. Modal sosial kelompok mangrove di Desa Margasari dan Desa Muara Gading Mas adalah sebagai berikut (a) kelompok dan jaringan yang termasuk kategori rendah ada $93 \%$ dan $100 \%$, (b) kepercayaan dan solidaritas yang termasuk dalam kategori rendah ada $85 \%$ dan $76 \%$, (c) aspek kolektif dan kerjasamayang termasuk kategori rendah ada $80 \%$ dan $94 \%$, (d) informasi dan komunikasiyang termasuk kategori minimum ada $67 \%$ dan kategori rendah ada 53\%, (e) aspek kohesi dan inklusi yang termasuk kategori rendah ada $63 \%$ dan $94 \%$ dan (f) aksi pemberdayaan dan aksi politik yang termasukkategori rendah ada $96 \%$ dan $100 \%$.
\end{abstract}

Kata Kunci : modal sosial, karakteristik sosial ekonomi, hutan mangrove, kelompok masyarakat

\section{ABSTRACT}

The sustainability of mangrove forest management was required social capital. Social capital wassociety capability to made relation each other and built the power that very important not only for economic life of the community but also other socialexistantion. This research aimed to know the social economiccharacteristic and social capital communities that managed and conserved the mangrove forest in Labuhan Maringgai district of East Lampung Regency. The study used quantitative and qualitative analysis. The method used descriptive and scoring method. The results showed that social economic characteristic atMargasari village had much in common with the majority of Muara Gading Mas village and the social capital in Margasari dan Muara Gading Mas village community groups was low. Social capital group of mangrove in Margasari and 
Muara Gading Mas village were (a) group and network was low in 93\% and 100\%, (b) trust and solidarity was low in $85 \%$ and $76 \%,(c)$ aspects of collective and cooperative was low in $80 \%$ and $94 \%,(d)$ information and communications was minimum in $67 \%$ and low in 53\%, (e) aspects of cohesion and inclusion was low in $63 \%$ and $94 \%$ and $(f)$ actions of empowerment and political was low in $96 \%$ and $100 \%$.

Keywords: social capital, social economic characteristic, mangrove forest, community group

\section{PENDAHULUAN}

\section{Latar Belakang}

Hutan mangrove adalah tipe hutan yang khas terdapat di sepanjang pantai atau muarasungai yang dipengaruhi oleh pasang surut air laut.Lampung Timur merupakan salah satu kabupaten yang memiliki hutan mangrove.Hutan mangrove di Lampung Timur di konversi untuk fungsi lain dengan membuka 13 tambak udang dan abrasi pantai tahun 1990-1994(Kustantidkk, 2014a). Kondisi hutan mangrove Desa Margasari tahun 1970an desa ini memiliki luasan hutan mangrove setebal 700 meter ke arah laut. Tahun 1983 masyarakat melakukan penebangan untuk penambakan udang tradisional kurang lebih 300 meter ke arah laut. Penebangan ini dilakukan oleh perorangan atau pun kelompok masyarakat. Tahun 1994 terjadi abrasi besar-besaran sampai 500 meter kearah daratan yang mengakibatkan tambak-tambak yang telah ada menjadi hilang dan berubah menjadi lautan. Setelah terjadinya peristiwa tersebut dilakukan rehabilitasi terhadap hutan mangrove dan hingga saat ini kondisi hutan mangrove di Desa Margasari bertambah luasan mangrovenya. Peningkatan luas hutan mangrove sudah mencapai 817,59 ha (Putra, 2014).Berbeda dengan Desa Muara Gading Mas yang hutan mangrovenya mengalami kerusakan pada era tahun 1976 ada pembukaan tambak yang pertama seluas 14 ha dan tahun 1980 terjadi perluasan tambak udang yang sangat cepat disepanjang pantai timur. Tahun 1990-an perkembangan usaha tambak udang semakin pesat yang ditandai dengan konversi lahan secara besar-besaran di kawasan hutan mangrove untuk lahan tambak.Kondisi hutan mangrove saat ini di Desa Muara Gading Mas mengalami kerusakan dan dalam tahap rehabilitasi dimana pada tahun 2007 ada kegiatan penanaman pertama sebanyak 75.000 bibit.Tahun 2013 ada kegiatan penanaman bibit sebanyak 65.000 bibit. Kondisi hutan mangrove di Desa Muara Gading Mas memiliki kerapatan mangrove yang rendah karena sangat jarang ditemukan fase pohon serta luasan hutan mangrove yang tidak mencapai 1 ha. Luas hutan mangrove di Desa Muara Gading Mas adalah 0 ha (Putra, 2014).

Kondisi hutan mangrove yang ada diDesa Margasari dan Muara Gading Mas membutuhkan rehabilitasi hutan yang efektif dan pengelolaan terpadu.Menurut Kustantidkk(2014b) bahwa dalam pengelolaan hutan mangrove terpadu sangat dibutuhkan peran masing-masing stakeholder yang terlibat dalam pengelolaan tersebut. Pengelolaan hutan mangrove di Desa Margasari dan Muara Gading Mas melibatkan masyarakat setempat dan kondisi hutan mangrove dikedua desa tersebut mulai membaik dan ada yang tetap mengalami kerusakan itu tidak lepas karena adanya modal sosial yang dimiliki masyarakat setempat yang mengelola dan memanfaatkan hutan mangrove. Salah satu modal yang sangat berperan dalam proses pembangunan yaitu modal sosial agar tercapai pengelolaan hutan mangrove secara lestari dan berkelanjutan (Lampung Mangrove Center, 2010).Menurut Thobias (2013) modal sosial yang dimiliki masyarakat seperti kepercayaan,gotong royong, jaringan dan sikap, memiliki pengaruh yang besar terhadap perkembangan perilaku masyarakat serta modal sosial bila dikelola dengan baik dan benar 
akan lebih mampu memberdayakan masyarakat. Modal sosial merupakan strategi yang baik digunakan untuk pendekatan dalam pemberdayaan masyarakat terutama dalam pengembangan ekonomi pedesaan.

Modal sosial juga memiliki hubungan dengan sosial ekonomi masyarakat dimana menurut Burt (1992) modal sosial merupakan kemampuan masyarakat untuk melakukan hubungan satu sama lain dan menjadi kekuatan yang sangat penting bagi kehidupan ekonomi masyarakat dan juga aspek eksistensi sosial yang lain. Aktivitas ekonomi masyarakat merupakan bagian yang penting dari kehidupan sosial yang diikat oleh normanorma, aturan-aturan dan kewajiban-kewajiban. Berdasarkan latar belakang diatas maka diperlukan penelitian mengenai modal sosial masyarakat pada pengelolaan dan pelestarian hutan mangrove di Desa Margasari dan Desa Muara Gading Mas Kecamatan Labuhan Maringgai Kabupaten Lampung Timur. Penelitian ini dilakukan untuk mengetahui karakteristik sosial ekonomi dan modal sosialmasyarakat dalam pengelolaan dan pelestarian hutan mangrove di Kecamatan Labuhan Maringgai Kabupaten Lampung Timur.

\section{METODE PENELITIAN}

Penelitiandilakukan pada bulan September sampai dengan November 2014. Lokasi penelitian adalahDesa Margasari dan Desa Muara Gading MasKecamatan Labuhan Maringgai Kabupaten Lampung Timur.Kedua desa ini dipilih secara sengaja (purposive) menjadi lokasi penelitian karena dianggap dapat mewakili kondisi mangrove di Kecamatan Labuhan Maringgai Kabupaten Lampung Timur.Kondisi mangrove di Desa Muara Gading Mas telah rusak dan hutan mangrove yang ada di Desa Margasari menurut surat keputusan BupatiLampung Timur merupakan hutan pendidikan Unilaseluas $700 \mathrm{Ha}$ (Kustanti dkk, 2014a) yang memiliki kondisi hutan mangrove yang baik.Objek penelitian ini adalah masyarakat anggota kelompok mangrove di Desa Margasari dan Muara Gading Mas serta anggota kelompok non mangrove di Desa Margasari.

Jenis data yang digunakan dalam penelitian ini adalah data primer dan data sekunder. Data primer adalah 1) karakteristik sosial ekonomi yaitu mata pencaharian, pendidikan formal, pendidikan non formal, pendapatan pokok, pendapatan mangrove, jenis kelamin, umur, kepemilikan luas lahan, jumlah tanggungan keluarga dan jumlah anggota keluarga yang bekerja. 2) modal sosial yaitu grupdan jaringan, kepercayaan dansolidaritas, kolektiftindakan dankerja sama,kohesi daninklusisosial, informasi dankomunikasi, danPemberdayaan aksi politik.Data sekunder berupa data gambaran umum Desa Margasari dan Desa Muara Gading Mas.

Jumlah populasi kelompok mangrove dan non mangrove Desa Margasari adalah 269 kepala keluarga dan populasi kelompok mangrove Desa Muara Gading Mas adalah 55 kepala keluarga.Jumlah sampel yang digunakan pada penelitian ini berjumlah 63 responden. Pengambilan sampel untuk data berupa karakteristik sosial ekonomi, modal sosial dan kerakteristik individu dilakukan dengan menggunakan metode simple random sampling.

Data dan informasi yang diperoleh dalam penelitian dianalisis secara kualitatif dan kuantitatifdenganmenggunakan metode deskriptifdan scoring. Pengolahan dan analisis data kuantitatif dilakukan secara bertahap dimulai dengan pengelompokkan data, perhitungan penyesuaian dengan kalkulator, dan tabulasi data. 


\section{HASIL DAN PEMBAHASAN}

\section{A. Karakteristik Sosial Ekonomi}

Karakteristik sosial ekonomi merupakan sifat yang melekat pada individu masyarakat. Karakteristik tersebut akan mempengaruhi kondisi ekonomi individu. Karakteristik sosial ekonomi dalam penelitian ini dapat disajikan dalam tabel sebagai berikut:

\begin{tabular}{|c|c|c|c|c|c|}
\hline \multirow[b]{2}{*}{ No } & \multirow[b]{2}{*}{ Karakteristik sosial ekonomi } & \multicolumn{2}{|c|}{ Desa Margasari } & \multicolumn{2}{|c|}{ Desa Muara Gading Mas } \\
\hline & & Jumlah & Persen $(\%)$ & Jumlah & Persen $(\%)$ \\
\hline \multirow[t]{5}{*}{1.} & Pekerjaan & & & & \\
\hline & - Petani & 27 & 59 & 7 & 41 \\
\hline & - Nelayan & 10 & 22 & 10 & 59 \\
\hline & - $\mathrm{PNS}$ & 6 & 13 & - & - \\
\hline & - Wiraswasta & 3 & 6 & - & - \\
\hline \multirow[t]{4}{*}{2.} & Pendidikan & & & & \\
\hline & - $\mathrm{SD}$ & 18 & 39 & 9 & 53 \\
\hline & - SMP & 16 & 35 & 8 & 47 \\
\hline & - SMA-SI & 12 & 26 & - & - \\
\hline \multirow[t]{3}{*}{3.} & Pendidikan non-formal & & & & \\
\hline & - Pernah & 27 & 59 & 12 & 71 \\
\hline & - Tidak Pernah & 19 & 41 & 5 & 29 \\
\hline \multirow[t]{4}{*}{4.} & Pendapatan pokok & & & & \\
\hline & $\bullet<500 \mathrm{rb}$ & - & - & - & - \\
\hline & - $500 \mathrm{rb}-1 \mathrm{jt}$ & 14 & 30 & 1 & 6 \\
\hline & - > $1 \mathrm{jt}$ & 32 & 70 & 16 & 94 \\
\hline \multirow[t]{4}{*}{5.} & Pendapatan mangrove & & & & \\
\hline & - Tidak ada & 42 & 91 & 17 & 100 \\
\hline & $\bullet<500 \mathrm{rb}$ & 1 & 2 & - & - \\
\hline & - > 500rb & 3 & 7 & - & - \\
\hline \multirow[t]{4}{*}{6.} & Jumlah tanggungan keluarga & & & & \\
\hline & - $<3$ orang & 21 & 46 & 9 & 53 \\
\hline & - $3-5$ orang & 24 & 52 & 7 & 41 \\
\hline & - $>5$ orang & 1 & 2 & 1 & 6 \\
\hline \multirow[t]{4}{*}{7.} & $\begin{array}{l}\text { Jumlah anggota keluarga yang } \\
\text { bekerja }\end{array}$ & & & & \\
\hline & - 1 orang & 4 & 9 & 3 & 18 \\
\hline & - 2 - 3 orang & 41 & 89 & 14 & 82 \\
\hline & - > 3 orang & 1 & 2 & - & \\
\hline \multirow[t]{4}{*}{8.} & $\begin{array}{l}\text { Kepemilikan } \\
\text { lahan }\end{array}$ & & & & \\
\hline & - Tidak punya & 5 & 11 & 6 & 35 \\
\hline & - $<1$ ha & 21 & 46 & 9 & 53 \\
\hline & - > 1 ha & 20 & 43 & 2 & 12 \\
\hline \multirow[t]{3}{*}{9.} & Jenis Kelamin & & & & \\
\hline & - Laki-laki & 38 & 83 & 17 & 100 \\
\hline & - Perempuan & 8 & 17 & - & - \\
\hline \multirow[t]{4}{*}{10.} & Umur & & & & \\
\hline & $\bullet<30$ tahun & 3 & 7 & - & - \\
\hline & - <30-55 tahun & 34 & 74 & 17 & 100 \\
\hline & - > 55 tahun & 9 & 19 & - & - \\
\hline
\end{tabular}

Hasil penelitian menunjukan bahwa karakteristik sosial ekonomi di Desa Margasari dan Desa Muara Gading Mas adalah sebagai berikut: a) pendidikan formal masyarakat kedua desa mayoritas tahapSekolah Dasar (SD), hal ini menunjukan bahwa pendidikan masih tergolong rendah. Pendidikan yang tinggi akan mempengaruhi mata pencaharian atau pekerjaan seorang individu. Individu yang memiliki bekal pengetahuan dan jenjang 
pendidikan yang tinggi akan berusaha keras memperoleh pekerjaan yang baik untuk memenuhi kebutuhannya. b) tingkat pendidikan non formal di Desa Margasari dan Desa Muara Gading Mas mayoritas anggota kelompok pernah mengikuti kegiatan penyuluhan, pelatihan dan kursus mengenai mangrove. c) pendapatan pokok di kedua desa mayoritas lebih dari 1 juta. Tingkat pendapatan merupakan salah satu faktor yang penting dalam pemenuhan kebutuhan hidup sehari-hari individu. d) jumlah anggota keluarga yang bekerja di Desa Margasari dan Desa Muara Gading Mas mayoritas berkisar 2 sampai 3 orang. Jumlah anggota keluarga yang bekerja dapat mempengaruhi pendapatan yang diterima oleh suatu keluarga. e) kepemilikan luas lahan anggota kelompok yang terdapat di Desa Margasari dan Desa Muara Gading Mas mayoritas kurang dari 1 ha. f) jenis kelamin anggota kelompok di kedua desa pada umumnya laki-laki. Jenis kelamin dapat mempengaruhi kebutuhan sosial ekonomi. Laki-laki akan lebih berusaha dan giat dalam bekerja dalam meningkatkan pendapatan dalam pemenuhan kebutuhan ekonomi. g) umur anggota kelompok di Desa Margasari dan Desa Muara Gading Mas mayoritas antara 30 sampai 55 tahun. Kondisi ini menunjukan bahwa kedua desa memiliki sebaran umur yang produktif. Menurut Ichwandi (2001) menyebutkan bahwa usia produktif menunjukan tersedianya sumber tenaga kerja yang baik karena umur produktif akan lebih mudah menerima perubahan, ide-ide dan inovasi. h) pendapatan mangrove merupakan pendapatan dari hasil pengolahan mangrove, penjualan bibit mangrove dan lain-lain. Desa Margasari dan Desa Muara Gading Mas mayoritas tidak memiliki pendapatan dari mangrove. i) mata pencaharian yaitu sebagian besar masyarakat yang tinggal disekitar hutan mangrove di wilayah pesisir bermata pencaharian sebagai nelayan, sebagian lainnya petani, karyawan, wirawasta, pertukangan, buruh tani dan jasa. Desa Margasari memiliki mata pencaharian mayoritas petani tambak sedangkan Desa Muara Gading Mas mayoritas nelayan dan j) jumlah tanggungan keluarga di Desa Margasari mayoritas berkisar 3 sampai 5 orang sedangkan Desa Muara Gading Mas berkisar kurang dari 3 orang.

\section{B. Modal Sosial}

Modal sosial merupakanserangkaian nilai-nilai atau norma-norma yang diwujudkan dalam perilaku yang dapat mendorong kemampuan dan kapabilitas untuk bekerja sama dan berkoordinasi untuk menghasilkan kontribusi besar terhadap keberlanjutan produktivitas.

\section{a. Kelompok dan Jaringan}

Kelompok merupakan kumpilan orang yang berinteraksi saling bergantung dan jaringan merupakan sebuah koneksi hubungan sosial individu kelompok. Tabel tingkatan kelompok dan jaringan adalah sebagai berikut:

Tabel 2. Tingkatan kelompok dan jaringan di Desa Margasari dan Muara Gading Mas.

\begin{tabular}{|c|c|c|c|c|c|c|c|c|c|c|c|c|c|c|}
\hline \multirow{3}{*}{ No } & \multirow{3}{*}{ Kategori } & \multicolumn{13}{|c|}{ ¿Anggota Kelompok Masyarakat } \\
\hline & & \multicolumn{7}{|c|}{ Desa Margasari } & \multicolumn{4}{|c|}{$\begin{array}{c}\text { Muara Gading } \\
\text { Mas }\end{array}$} & \multirow{2}{*}{$\sum$} & \multirow{2}{*}{$\%$} \\
\hline & & MJS & MJU & PLH & $\mathrm{T}$ & $\mathrm{N}$ & KT & PI & & & $\mathrm{PU}$ & PTPM & & \\
\hline 1. & Tinggi & - & - & - & - & - & - & - & - & - & - & - & - & - \\
\hline 2. & Sedang & 3 & - & - & - & - & - & - & 3 & 7 & - & - & - & - \\
\hline 3. & Rendah & - & 3 & 8 & 2 & 6 & 22 & 2 & 43 & 93 & 3 & 14 & 17 & 100 \\
\hline \multirow[t]{2}{*}{4.} & Minimum & - & - & - & - & - & - & - & - & - & - & - & - & - \\
\hline & Jumlah & 3 & 3 & 8 & 2 & 6 & 22 & 2 & 46 & 100 & 3 & 14 & 17 & 100 \\
\hline
\end{tabular}

Sumber : Data Primer, 2014 
Keterangan: MJS (Marga Jaya Satu PLH (Pendidikan Lingkungan Hidup)

KT (Kelompok Tani)

$\mathrm{N}$ (Nelayan)

Kelompok dan jaringan masyarakat yang terdapat di Desa Margasari mayoritas termasuk kategori rendah, hal ini dikarenakan kelompok masyarakat sudah jarang melakukan kegiatan mangrove sehingga banyak anggota kelompok yang tidak aktif.Salah satu contoh yaitu kelompok Marga Jaya Utama yangterdaftar sebagai anggota kelompok tetapi ketika diwawancarai mengatakan tidak merasa menjadi anggota kelompok. Penyebabnya adalah ketika ada kegiatan kelompok anggota tersebut tidak terlibat.

Kelompok dan jaringan masyarakat di Desa Muara Gading Mas termasuk kategori rendah karena kedua kelompok mangrovenya sudah jarang melakukan pertemuan dengan sesama anggota kelompok.Kelompok-kelompokakan aktif kembali ketika sudah menerima suatu program dari pemerintah misalnya kelompok PetaniTambak Pelindung Mangrove. Kelompok yang dibentuk dua tahun lalu ketika diwawancarai mengenai kegiatan kelompok saat ini, anggota kelompok mengatakan tidak ada kegiatan karena pemerintah tidak memberikan program.Kelompok ini bahkan tidak pernah berinteraksi atau saling berhubungan dengan kelompok masyarakat lain seperti kelompok Panca Usaha.

Desa Margasari untuk pengembangan jejaring kerja berhubungan denganUniversitas Lampung, Pemerintah Daerah Lampung Timur sejak tahun 2005, pada bulan Januari tahun 2009 dikembangkan kerjasama antaraSub-Sector Program on Mangrove Japan International Cooperation Agency(JICA) dan Balai Pengelola Hutan Mangrove (BPHM) Wilayah II. Jaringan pada Desa Muara Gading Mas masih berhubungan dengan pemerintah dan LSM.

\section{b. Kepercayaan dan Solidaritas}

Kepercayaan merupakan kemauan seseorang untuk bertumpu pada orang lain karena kita memiliki keyakinan terhadap orang lain tersebut. Kepercayaan berhubungan dengan solidaritas yaitu rasa kebersamaan, rasa kesatuan kepentingan dan rasa simpati. Tingkatan kepercayaan dan solidaritas terdapat pada tabel berikut:

Tabel 3. Tingkatan kepercayaan dan solidaritas di Desa Margasari dan Muara Gading Mas.

\begin{tabular}{|c|c|c|c|c|c|c|c|c|c|c|c|c|c|c|}
\hline \multirow{3}{*}{ No } & \multirow{3}{*}{ Kategori } & \multicolumn{13}{|c|}{ ¿Anggota Kelompok Masyarakat } \\
\hline & & \multicolumn{7}{|c|}{ Desa Margasari } & $\sum$ & $\%$ & \multicolumn{2}{|c|}{$\begin{array}{c}\text { Muara Gading } \\
\text { Mas }\end{array}$} & \multirow[t]{2}{*}{$\sum$} & \multirow[t]{2}{*}{$\%$} \\
\hline & & MJS & MJU & PLH & $\mathrm{T}$ & $\mathrm{N}$ & KT & PI & & & PU & PTPM & & \\
\hline 1. & Tinggi & - & - & - & - & - & - & - & - & - & - & - & - & - \\
\hline 2. & Sedang & 1 & - & - & - & 1 & - & - & 2 & 4 & 1 & 3 & 4 & 24 \\
\hline 3. & Rendah & 2 & 1 & 8 & 1 & 5 & 20 & 2 & 39 & 85 & 2 & 11 & 13 & 76 \\
\hline 4. & Minimum & - & 2 & - & 1 & - & 2 & - & 5 & 11 & - & - & - & - \\
\hline & Jumlah & 3 & 3 & 8 & 2 & 6 & 22 & 2 & 46 & 100 & 3 & 14 & 17 & 100 \\
\hline
\end{tabular}

Sumber : Data Primer, 2014.

Kepercayaan dan solidaritas pada kelompok masyarakat di Desa Margasari dalam kategori rendah. Kelompok Marga Jaya Utama merupakan salah satu kelompok yang sesama anggota memiliki rasa saling percaya satu sama laintetapi untuk tingkat rasa percaya sesama anggota kelompok tersebut dari tahun ke tahun tetap sama dan tidak berubah. Menurut hasil penelitian Yuliarmi (2013) bahwa terjalin hubungan baik antar 
anggota kelompok dalam suatu ikatan organisasi sosial kemasyarakatan seperti lembaga adat akan membentuk suatu kepercayaan bahwa ikatan tersebut dapat terjalin secara berkesinambungan dalam jangka panjang sehingga ada keterikatan yang saling menguntungkan.Kelompokmasyarakat di Desa Margasari mayoritas anggota kelompok masih sedikit yang dapat menjadi tempat berkeluh kesah ketika terkena suatu masalah.Menurut Zulfanarisyandra (2009) tanpa adanya rasa percaya yang terjalin antara anggota kelompok dan pengurus masalah yang terjadi tidak akan terselesaikan.

Tingkat kepercayaan dan solidaritaskelompok masyarakat di Desa Muara Gading Masdalam kategori rendah.Sesama anggota kelompok di kelompok Panca Usaha memang saling percayatetapitingkat rasa kepercayaan tersebut dari tahun ke tahun tetap sama. Berbeda dengan kelompok Petani Tambak Pelindung Mangrove bahwa tingkat rasa percaya anggota kelompok baik karena kelompok baru dibentuk. Jika anggota kelompok Panca Usaha dan Petani Tambak Pelindung Mangroveterkena masalah hanya beberapa anggota kelompok yang dapatmembantu dan menjadi tempat berkeluh kesah.Menurut hasil penelitian Cahyono (2012) solidaritas antarwarga dapat dilihat dengan rasa memiliki antar anggota sehingga kerukunan dan persatuan warga meningkat yaitu cara silahturahmi, bertukar pengalaman dan kekompakan.Solidaritas yang tinggi menekankan pada kebersamaan sehingga solidaritas dapat muncul akibat adanya interaksi antar individu sehingga individu-individu melakukan sebuah kerjasama (Coleman, 1999).

\section{c. Aspek Kolektif dan Kerjasama}

Aksi kolektif merupakan pengambilan keputusan bersama untuk kepentingan bersama dan kerjasama merupakan suatu usaha bersama antara orang perorangan atau kelompok untuk mencapai tujuan bersama. Tingkatan aksi kolektif dan kerjasama dapat dilihat pada tabel dibawah ini:

Tabel 4. Tingkatan aksi kolektif dan kerjasama di Desa Margasari dan Muara Gading Mas.

\begin{tabular}{|c|c|c|c|c|c|c|c|c|c|c|c|c|c|c|}
\hline \multirow{4}{*}{ No } & \multirow{4}{*}{ Kategori } & \multicolumn{13}{|c|}{ EAnggota Kelompok Masyarakat } \\
\hline & & \multirow{2}{*}{\multicolumn{7}{|c|}{ Desa Margasari }} & \multirow{2}{*}{\multicolumn{4}{|c|}{$\begin{array}{c}\text { Muara Gading } \\
\text { Mas }\end{array}$}} & \multirow{3}{*}{$\Sigma$} & \multirow{3}{*}{$\%$} \\
\hline & & & & & & & & & & & & & & \\
\hline & & MJS & MJU & PLH & $\mathrm{T}$ & $\mathrm{N}$ & KT & PI & & & $\mathrm{PU}$ & PTPM & & \\
\hline 1. & Tinggi & - & - & - & - & - & - & - & - & - & - & - & - & - \\
\hline 2. & Sedang & - & - & - & - & - & - & - & - & - & - & - & - & - \\
\hline 3. & Rendah & 3 & 2 & 6 & - & 5 & 19 & 2 & 37 & 80 & 3 & 13 & 16 & 94 \\
\hline \multirow[t]{2}{*}{4.} & Minimum & - & 1 & 2 & 2 & 1 & 3 & - & 9 & 20 & - & 1 & 1 & 6 \\
\hline & Jumlah & 3 & 3 & 8 & 2 & 6 & 22 & 2 & 46 & 100 & 3 & 14 & 17 & 100 \\
\hline
\end{tabular}

Sumber : Data Primer, 2014.

Aksi kolektif dan kerjasama pada kelompok masyarakat yang terdapat di Desa Margasari tergolongrendah, dilihat dari hasil penelitian dilapangan. Desa Margasari memiliki beberapa kelompok masyarakat yang mayoritas kelompoknya tidak pernah melakukan kegiatan bersama anggota kelompok diluar dari program yang telah diberikan pemerintah misalnya kelompokMarga Jaya Utama dan PLH akan tetapi dulunya ada beberapa kelompok yang pernah memiliki kegiatan dengan JICA, contoh kegiatannya yaitu tahun 2009 dilakukanpemberdayaan masyarakat tentang pengelolaan hutan terpadu, kerjasama antara JICA dan Balai Pengelola Hutan Mangrove (BPHM) Wilayah II dan pengembangan UMKM. Kemudian jika suatu kelompok melakukan kegiatan tidak pernah ada sanksi yang diberikan kepada anggota kelompok ketika tidak mengikuti kegiatan tersebut. 
Tingkat aksi kolektif dan kerjasama di Desa Muara Gading Mas masih dalam kategori rendah, kelompok tersebut tidak pernah melakukan kegiatan bersama anggota kelompok dan hal ini sama dengan kelompok masyarakat yang terdapat di Desa Margasari. Anggota kelompok biasanya jika bergabung dalam kelompok masyarakat ada yang secara sukarela dan diberi uang lelah. Menurut Pranadji (2006) bahwa pemberdayaan masyarakat untuk pengelolaan lahan di pedesaan secara berkelanjutan tidak cukup dilandaskan pada pemberian material melainkan harus juga mempertimbangkan penguatan semangat kerja kolektif dan menghormati sumberdaya milik bersama.

Desa Margasari dalam aspek kerjasama dalam pengelolaan hutan mangrove menggunakan pendekatan pengelolaan Tripartit yaitu masyarakat, Universitas Lampung dan Pemerintah Daerah Kabupaten Lampung Timur. Pengelolaan hutan mangrove yang sesuai dengan tugas pokok dan fungsi stakeholder tanpa ada alineasi diantara pihak yang bekerjasama (Kustantidkk, 2014b). Berbeda dengan di Desa Muara Gading Mas yang bekerjasama hanya dengan LSM misalnya WATALA akan tetapi pemerintah memiliki peran dalam aksi kolektif pada kelompok yang terdapat di Desa Muara Gading Mas.

\section{d. Apek Informasi dan Komunikasi}

Komunikasi dan informasi merupakan suatu proses sesorang atau beberapa orang, kelompok, organisasi, dan masyarakat menciptakan dan menggunakan informasi agar terhubung dengan lingkungan dan orang lain. Tabel tingkatan aspek informasi dan komunikasi dapat dilihat sebagai berikut:

Tabel 5. Tingkatan informasi dan komunikasi di Desa Margasari dan Muara Gading Mas.

\begin{tabular}{|c|c|c|c|c|c|c|c|c|c|c|c|c|c|c|}
\hline \multirow{4}{*}{ No } & \multirow{4}{*}{ Kategori } & \multicolumn{13}{|c|}{ ¿Anggota Kelompok Masyarakat } \\
\hline & & \multirow{2}{*}{\multicolumn{7}{|c|}{ Desa Margasari }} & \multirow{2}{*}{\multicolumn{4}{|c|}{$\begin{array}{c}\text { Muara Gading } \\
\text { Mas }\end{array}$}} & \multirow{3}{*}{$\Sigma$} & \multirow{3}{*}{$\%$} \\
\hline & & & & & & & & & & & & & & \\
\hline & & MJS & MJU & PLH & $\mathrm{T}$ & $\mathrm{N}$ & KT & PI & & & PU & PTPM & & \\
\hline 1. & Tinggi & - & - & - & - & - & - & - & - & - & - & - & - & - \\
\hline 2. & Sedang & - & - & - & - & - & - & - & - & - & - & - & - & - \\
\hline 3. & Rendah & 2 & - & 2 & 1 & 5 & 5 & - & 15 & 33 & 1 & 8 & 9 & 53 \\
\hline \multirow[t]{2}{*}{4.} & Minimum & 1 & 3 & 6 & 1 & 1 & 17 & 2 & 31 & 67 & 2 & 6 & 8 & 47 \\
\hline & Jumlah & 3 & 3 & 8 & 2 & 6 & 22 & 2 & 46 & 100 & 3 & 14 & 17 & 100 \\
\hline
\end{tabular}

Sumber : Data Primer, 2014.

Hasil penelitian menunjukan bahwa aspek informasi dan komunikasi di Desa Margasari termasuk dalam kategori minimum. Anggota kelompok tidak selalu mengetahui perkembangan kegiatan kelompok, setiap kelompok masyarakat sangat jarang mengadakan pertemuan sehingga ketika ada informasi mengenai kegiatan kelompok cara penyampaiannya dengan telepon serta informasi yang diperoleh selalu dari ketua kelompok. Menurut hasil penelitian Cahyono (2012), nilai-nilai kepercayaan dalam masyarakat dapat dilihat dari frekuensi pertemuan yang cenderung rutin dalam kelembagaan setiap bulannya.

Desa Muara Gading Mas untuk aspek informasi dan komunikasi berdasarkan hasil penelitian termasuk dalam kategori rendah. Kelompok masyarakat di Desa Muara Gading Mas selalu mengetahui perkembangan informasi kelompok contohnya adalah Petani Tambak Pelindung Mangrove yang baru dibentuk tahun 2013. Anggota kelompok biasanya memperoleh informasi dari pengurus dan kadang-kadang ketua kelompok. Suatu kelompok masyarakat seharusnya lebih banyak mengetahui informasi-informasi kelompok. Informasi sangatlah penting sebagai basis tindakan. Individu yang memiliki jaringan lebih 
luas akan lebih mudah dan murah untuk memperoleh informasi, sehingga bisa dikatakan modal sosialnya tinggi dan demikian pula dengan sebaliknya (Coleman, 1999).

\section{e. Aspek Kohesi Sosial dan Inklusi}

Kohesi sosial dan inklusi merupakan kenyamanan individu yang bergabung dan berinteraksi dalam kelompok. Tingkatan aspek kohesi dan inklusi terdapat pada tabel berikut:

Tabel 6. Tingkatan kohesi sosial dan inklusi di Desa Margasari dan Muara Gading Mas.

\begin{tabular}{|c|c|c|c|c|c|c|c|c|c|c|c|c|c|c|}
\hline \multirow{4}{*}{ No } & \multirow{4}{*}{ Kategori } & \multicolumn{13}{|c|}{ EAnggota Kelompok Masyarakat } \\
\hline & & \multirow{2}{*}{\multicolumn{7}{|c|}{ Desa Margasari }} & \multirow{3}{*}{$\Sigma$} & \multirow{3}{*}{$\%$} & \multirow{2}{*}{\multicolumn{2}{|c|}{$\begin{array}{c}\text { Muara Gading } \\
\text { Mas }\end{array}$}} & \multirow{3}{*}{$\sum$} & \multirow{3}{*}{$\%$} \\
\hline & & & & & & & & & & & & & & \\
\hline & & MJS & MJU & PLH & $\mathrm{T}$ & $\mathrm{N}$ & KT & PI & & & PU & PTPM & & \\
\hline 1. & Tinggi & - & - & - & - & - & - & - & - & - & - & - & - & - \\
\hline 2. & Sedang & - & - & - & - & - & - & - & - & - & - & 1 & 1 & 6 \\
\hline 3. & Rendah & 1 & 3 & 5 & 2 & 1 & 15 & 2 & 29 & 63 & 3 & 13 & 16 & 94 \\
\hline 4. & Minimum & 2 & - & 3 & - & 5 & 7 & - & 17 & 37 & - & - & - & - \\
\hline & Jumlah & 3 & 3 & 8 & 2 & 6 & 22 & 2 & 46 & 100 & 3 & 14 & 17 & 100 \\
\hline
\end{tabular}

Sumber : Data Primer, 2014.

Aspek kohesi sosial dan inklusi pada setiap kelompok Desa Margasari dan Desa Muara Gading Mas termasuk dalam kategori rendah. Kelompok masyarakat di Desa Muara Gading Mas pernah terjadi konflik diantaranya konflik antar anggota kelompok. Konflik tersebut disebabkan salah paham misalnya ketika rapat ada yang berbeda pendapat sedangkan konflik di Desa Margasarimerupakan konflik kelompok dengan masyarakat yaitu masyarakat melanggar aturan-aturan yang masyarakat belum mengetahuinya. Kelompok di kedua desa ketika meghadapi suatu konflik/masalah cara penyelesaiannya adalah musyawarah. Kelompok-kelompok masyarakat yang terdapat di Desa Muara Gading Mas dan Desa Margasari menyatakan bahwa anggota kelompoknya sangat jarang mengunjungi teman sesama anggota akan tetapi ketika ada anggota kelompok yang mengunjungi teman kelompok lainnya hal yang dibicarakan adalah kegiatan dan program kelompok.

\section{f. Aksi Pemberdayaan dan Aksi Politik}

Aksi pemberdayaan dan aksi politik merupakan proses pembangunan yang melibatkan masyarakat untuk memulai proses kegiatan sosial untuk situasi dan kondisi. Tabel tingkatan aksi pemberdayaan dan aksi politik adalah sebagai berikut:

Tabel 7. Tingkatan aksi pemberdayaan dan aksi politik di Desa Margasari dan Muara Gading Mas.

\begin{tabular}{|c|c|c|c|c|c|c|c|c|c|c|c|c|c|c|}
\hline \multirow{3}{*}{ No } & \multirow{3}{*}{ Kategori } & \multicolumn{13}{|c|}{ EAnggota Kelompok Masyarakat } \\
\hline & & \multicolumn{7}{|c|}{ Desa Margasari } & \multirow{2}{*}{$\Sigma$} & \multirow[t]{2}{*}{$\%$} & \multicolumn{2}{|c|}{$\begin{array}{c}\text { Muara Gading } \\
\text { Mas }\end{array}$} & \multirow[t]{2}{*}{$\sum$} & \multirow{2}{*}{$\%$} \\
\hline & & MJS & MJU & PLH & $\mathrm{T}$ & $\mathrm{N}$ & KT & PI & & & PU & PTPM & & \\
\hline 1. & Tinggi & - & - & - & - & - & - & - & - & - & - & - & - & - \\
\hline 2. & Sedang & 1 & - & - & - & - & 1 & - & 2 & 4 & - & - & - & - \\
\hline 3. & Rendah & 2 & 3 & 8 & 2 & 6 & 21 & 2 & 44 & 96 & 3 & 14 & 17 & 100 \\
\hline 4. & Minimum & - & - & - & - & - & - & - & - & - & - & - & - & - \\
\hline \multicolumn{2}{|r|}{ Jumlah } & 3 & 3 & 8 & 2 & 6 & 22 & 2 & 46 & 100 & 3 & 14 & 17 & 100 \\
\hline
\end{tabular}

Sumber : Data Primer, 2014. 
Aspek pemberdayaan dan aksi politik yang terdapat di Desa Margasari dan Desa Muara Gading Mas termasuk kategori rendah.Kelompok di kedua desamemiliki beberapa kelompok yang ada aturan dan tidak ada aturan.Kegiatan kelompok masyarakatdi Desa Margasari ada menjadi contoh bagi kelompok lain seperti kegiatan penanaman mangrove yang dilakukan oleh Pelestari Lingkungan Hidup (PLH) dan Marga Jaya Satu akan tetapikegiatan kelompok masyarakatdi Desa Muara Gading Mas belum pernah menjadi contoh bagi kelompok lain.Pengembangan masyarakat melibatkan pengembangan modal sosial, memperkuat interaksi sosial dalam masyarakat, menyatukan masyarakat dan membantu masyarakat untuk saling berkomunikasi dengan cara yang dapat mengarah pada dialog diantara sesama anggota kelompok, pemahaman dan aksi sosial. Aksi politik dari kelompok masyarakat di kedua desa adalah anggota kelompok di kedua desamayoritas pernah memilih pemimpin kelompok bagikelompok masing-masing.Anggota kelompok tidak pernahmemilih pemimpin kelompok berdasarkan suku, agama dan gender.

Pembahasan diatas merupakan perbandingan modal sosial kelompok mangrove di Desa Margasari yaitu Marga Jaya Satu, Marga Jaya Utama dan Pendidikan Lingkungan Hidup sedangkan Desa Muara Gading Mas yaitu Petani Tambak Pelindung Mangrove dan Panca Usaha.Penelitian ini juga meneliti modal sosial kelompok non mangrove di Desa Margasari yaitu kelompok Terasi, Nelayan, Kelompok Tani dan Pengolah Ikan.Modal sosial kelompok non mangrove Desa Margasari diteliti karena kelompoktesebut masih memanfaatkan mangrove.Salah satu kelompok yang memanfaatkan mangrove yaitu kelompok Terasi untuk membuat sirup, terasi, keripik dan lain-lain.Modal sosial kelompok non mangroveDesa Margasari masih tergolong rendah.Enam unsur-unsur modal sosial terhadap kelompok non mangrove adalah rendah.

Hasil penelitian menyatakan bahwa modal sosial di Desa Margasari dan Desa Muara Gading Mas termasuk dalam kategori rendah.Tingkatan keenam unsur-unsur modal sosial dalam penelitian mayoritas adalah rendah.Modal sosial yang lemah akan meredupkan semangat gotong royong, memperparah kemiskinan, meningkatkan pengangguran, kriminalitas, dan menghalangi setiap upaya untuk meningkatkan kesejahteraan penduduk. Menurut hasil penelitian Kamarni (2012) menyatakan modal sosial yang lemah mengundang munculnya pertentangan nilai dan menonjolnya rasa saling tidak percaya. Modal sosial dapat mengurangi kemiskinan dan meningkatkan kemampuan masyarakat, tidak sekedar jumlah tetapi kehidupan masyarakat yang lebih berarti.

Modal sosial terdiri dari beberapa komponen, yaitu relasi sosial, kepercayaan, dan norma. Relasi sosial yang dimaksud antara lain partisipasi, kerja sama, saling peduli, dan hubungan timbal balik.Kepercayaan dan norma dalam modal sosial dianggap sebagai komponen sangat penting karena menopang hubungan relasi sosial yang ada. Hal ini dapat diartikan jika tidak ada kepercayaan, maka hubungan relasi sosial yang ada tidak dapatdikatakan sebagai modal sosial (Anggita, 2013).Modal sosialyang tinggi akan mendorong efektifitas pemerintahan, beragam determinan memungkinkan negara berfungsi secara lebih efektif, memiliki legitimasi, dapat memfasilitasi hubungan antara negara dan rakyat.Menurut hasil penelitian Inayah (2012) modal sosial di tingkat desa dapat menjembatani hubungan pemerintah daerah dan masyarakat dalam menyebarkan informasi dan mengimplementasikan program-program pembangunan.

\section{KESIMPULAN}

1. Karakteristik sosial ekonomiDesa Margasari dan Desa Muara Gading Mas adalah sebagai berikut: (a) pendidikan formal tingkat SD ada39\% dan 53\%, (b) pendidikan non formal yang termasuk dalam kategori pernah ada $59 \%$ dan $71 \%$, (c) pendapatan pokok > 1 juta ada $70 \%$ dan $94 \%$, (d) jumlah anggota keluarga yang bekerja2-3 
orang ada $89 \%$ dan $82 \%$, (e) kepemilikan luas lahan $<1$ ha ada $46 \%$ dan $53 \%$, (f) jenis kelamin laki-laki ada $83 \%$ dan $100 \%$, (g) umur $<30-55$ tahun ada $74 \%$ dan $100 \%$, (h) pendapatan mangrove: $91 \%$ dan $100 \%$ yang tidak memiliki pendapatan mangrove, (i) mata pencaharian petani ada 59\% dan nelayan ada 59\% dan (j) jumlah tanggungan keluarga 3 - 5orang ada $52 \%$ dan $<3$ orang ada $53 \%$.

2. Modal sosial kelompok mangrove di Desa Margasari dan Desa Muara Gading Mas adalah sebagai berikut (a) kelompok dan jaringanyang termasuk kategori rendah ada 93\% dan $100 \%$, (b) kepercayaan dan solidaritas yang termasuk dalam kategori rendah ada $85 \%$ dan $76 \%$, (c) aspek kolektif dan kerjasamayang termasuk kategori rendah ada $80 \%$ dan $94 \%$, (d) informasi dan komunikasiyang termasuk kategori minimum ada $67 \%$ dan kategori rendah ada 53\%, (e) aspek kohesi dan inklusiyang termasuk kategori rendah ada $63 \%$ dan $94 \%$ dan (f) aksi pemberdayaan dan aksi politik yang termasuk kategori rendah ada $96 \%$ dan $100 \%$.

\section{DAFTAR PUSTAKA}

Anggita,T.2013.Dukungan modal sosial dalam kolektivitas usaha tani untuk mendukung kinerja produksi pertanian studi kasus: Kabupaten Karawang dan Subang.Jurnal Perencanaan Wilayah dan Kota.24(3):203-226.

Burt, R. S. 1992. Excerpt Jrom The SocialStructure of Competition, in Structure Holes:The Social Structure of Competition. Buku. Harvard. Cambridge, MA and London. $324 \mathrm{p}$.

Cahyono,Budi. 2012. Peran modal sosial dalam peningkatan kesejahteraan masyarakat petani tembakau di Kabupaten Wonosobo. Jurnal Conference In Business. Accounting and Management (CBAM).1(1):131-144.

Coleman, J. 1999. Social Capital in the Creation ofHuman Capital. Buku. Cambridge Mass. Harvard. $120 \mathrm{p}$.

Ichwandi, I. 2001. Dampak Krisis Ekonomi Terhadap Usaha Kehutanan Masyarakat: Studi Kasus di Kabupaten Maros, Sulawesi Selatan. Di dalam: Dudung D,editor. Resiliensi Kehutanan Masyarakat di Indonesia. Buku. Bogor. 141 p.

Inayah. 2012.Peranan modal sosial dalam pembangunan.Jurnal Pengembangan Humaniora. 12(1):43-49.

Kamarni, Neng.2012.Analisis modal sosial sebagai salah satu upaya dalam pengentasan kemiskinan (studi kasus: rumah tangga miskin di Kecamatan Koto Tangah Kota Padang). Jurnal Manajemen dan Kewirausahaan. 3(3):36-52.

Kustanti A., B. Nugroho., D. Nurrochmat., dan Y. Okimoto. 2014a.Evolusi hak kepemilikan dalam pengelolaan ekosistem hutan mangrove di Lampung Mangrove Center.Jurnal Kebijakan Pertanian dan Lingkungan.1(3):148-149.

Kustanti A., B. Nugroho., C. Kusmana., D. Darusman., D. Nurrochmat., M. Krott., dan C. Schusser. 2014b. Actor, interest and conflict in sustainable mangrove forest management.International Journal of Marine Science 2014.4(16):150_159.

LampungMangrove Center. Pengelolaan Kolaboratif Hutan Mangrove Berbasis Pemerintah dan Perguruan Tinggi. April 2010. 1 Mei 2014. http://www.kabarindonesia.com/berita.php?pil=4\&jd=Lampung+Mangrove+Center $\% 3 \mathrm{~A}+$ Pengelolaan+Kolaboratif+Hutan+Mangrove+Berbasis+Pemerintah\%2C+Mas yarakat+dan+Perguruan+Tinggi\&dn=20100405134927.

Pranadji, Tri. 2006. Penguatan modal sosial untuk pemberdayaan masyarakat pedesaan dalam pengelolaan agroekosistem lahan kering. Jurnal Agro Ekonomi.24(2):30-39. 
Putra, A. K. 2014. Perananan ekosistem hutan mangrove pada imunitas terhadap malaria (studi kasus di Kecamatan Labuhan Maringgai Kabupaten Lampung Timur). Jurnal Sylva Lestari. 3(2):67-78.

Thobias, E. 2013. Pengaruh modal sosial terhadap perilaku kewirausahaan (suatu studi pada pelaku usaha mikro kecil menengah di Kecamatan Kabaruan Kabupaten Kepulauan Talaud).Jurnal Acta Diurna.6(3):125-133.

Yuliarmi, N. 2013. Peran modal sosial dalam pemberdayaan industri kerajinan di Provinsi Bali. Jurnal Udayana.1(1):7-15.

Zulfianarisyandra.Penguatan Modal Sosial Dalam Usaha Pemberdayaan Masyarakat. 2009. 15 Mei 2015. https://zulfianarisyandra.wordpress.com/2009/05/26/penguatanmodal-sosial-dalam-usaha-pemberdayaan-masyarakat/. 